City University of New York (CUNY)

CUNY Academic Works

\title{
INDIVIDUALISM AND COLLECTIVISM IN AMERICA: THE CASE OF GUN OWNERSHIP AND ATTITUDES TOWARD GUN CONTROL
}

Katarzyna Celinska

CUNY John Jay College

\section{How does access to this work benefit you? Let us know!}

More information about this work at: https://academicworks.cuny.edu/jj_pubs/286

Discover additional works at: https://academicworks.cuny.edu

This work is made publicly available by the City University of New York (CUNY).

Contact: AcademicWorks@cuny.edu 


\title{
INDIVIDUALISM AND COLLECTIVISM IN AMERICA: THE CASE OF GUN OWNERSHIP AND ATTITUDES TOWARD GUN CONTROL
}

\author{
KATARZYNA CELINSKA \\ Rutgers University
}

\begin{abstract}
A number of sociologists and cultural psychologists claim that the United States is a predominantly individualistic country. This article uses a unidimensional index of individualism and collectivism to analyze one of the most debated sociopolitical issues in America: gun ownership and gun control. It tests the hypothesis that the widespread gun ownership in the United States and prevailing attitudes toward gun control represent competing individualistic and collectivistic cultural traditions, respectively. The findings indicate that the index is one of the predictors of gun ownership and of attitudes about gun permits. Keywords: individualism; collectivism; gun ownership; attitudes toward gun control
\end{abstract}

Many social and political controversies in America center on the tension between protecting individual rights and fulfilling the needs and interests of larger communities. This struggle between individualism and collectivism has been a focal concern of many prominent sociologists, including Bellah et al. (1985), Lipset (1990), and Putnam (2000). Each of them contends that American collectivism has been steadily declining as Americans focus more and more exclusively on their own self-interests. Although the concepts of individualism and collectivism are well established in sociological literature, few quantitative sociological studies actually examine their implications (Gouveia, Clemente, and Espinosa 2003). This article constructs and applies an index of individualism and collectivism to examine gun ownership and gun control in the United States.

The focus of this research is on utilitarian individualism, the component of individualism related to self-reliance-a value that is deeply rooted in American history and is associated with limited responsibility toward collectivity. The concept of utilitarian individualism, named as such by Bellah et al. in 1985, finds its roots in the sociology of Emile Durkheim (1893/1964, 1897/1951). The antithesis of

Direct all correspondence to: Katarzyna Celinska, PhD, Violence Institute of New Jersey, University of Medicine \& Dentistry of New Jersey, 151 Centennial Avenue, Piscataway, NJ 08854; phone: (732) 235-4171; fax: (732) 235-5828; e-mail: celinska@umdnj.edu.

Sociological Perspectives, Vol. 50, Issue 2, pp. 229-247, ISSN 0731-1214, electronic ISSN 1533-8673. (C) 2007 by Pacific Sociological Association. All rights reserved. Please direct all requests for permission to photocopy or reproduce article content through the University of California Press's Rights and Permissions website, at http://www.ucpressjournals.com/reprintinfo.asp. DOI: 10.1525/sop.2007.50.2.229. 
self-reliance is collectivism, which espouses sharing resources with others and, if necessary, relying on the government for fair and just distribution of collective resources. These two concepts are incorporated in this article into a single index, which treats extreme values of individualism and collectivism as opposite ends of a continuum.

In response to the lack of studies that assess quantitatively cultural dimensions of gun ownership, this construct of individualism and collectivism is employed as a predictor of gun ownership and attitudes toward gun control in America. In fact, gun ownership and the values of individualism have been bound tightly together throughout American history (Lipset 1990). In addition, literature and rhetorical debates suggest that the attitudes against gun control regulations among gun owners are one of the exceptions to the pattern that self-interest does not affect policy preferences (Wolpert and Gimpel 1998). Thus, using the construct of utilitarian individualism and collectivism might be especially appropriate for assessing their impact on attitudes toward gun control and, possibly, gun ownership.

\section{UTILITARIAN INDIVIDUALISM AND COLLECTIVISM}

\section{The Concept of Individualism and Collectivism}

Durkheim (1893/1964) made the concept of individualism and collectivism a focus of his discussion of the relationship between society and the individual in capitalistic, industrialized economies. He demarcated two types of solidarity to describe differences between "primitive" and "modern" societies and to chart the evolutionary changes that capitalism brought about for the relationship between the individual and the collectivity. Mechanical solidarity, which characterized "primitive" societies, absorbed the individual into community. In contrast, organic solidarity underlies societies characterized by industrialization, urbanization, growing population, and a specialized division of labor. The strong emotional bonds that tie people into the collective within "primitive" societies are replaced in modern, industrial societies by relationships of interdependence and a cult of individualism.

Although Durkheim (1897/1951) held a sanguine view of individualism, he also feared its excesses: anomie that occurs when the individuals' socially defined needs exceed their means and egoism that results when individuals focus exclusively on their own needs and detach from the larger group. He traces egoism directly to the weakening of collective social bonds:

If the individual isolates himself, it is because the ties uniting him with others are slackened or broken, because society is not sufficiently integrated at the points where he is in contact with it. These gaps between one and another individual consciousness, estranging them from each other, are authentic results of the weakening of the social fabric. (p. 281)

Thus, for Durkheim (1897/1951), anomie and egoism are interrelated. He states, "The egoist should have some tendency to nonregulation; for, since he is detached from society, it has not sufficient hold upon him to regulate him" (p. 288). According 
to Besnard (1993), Durkheim argued that a drive toward industrial prosperity might expand to all social institutions. As a result, anomie becomes chronic, structural, and institutionalized, manifesting in society's culture and dominant value system.

This concept of chronic anomie was adopted by a number of theorists, most importantly by Robert Merton (1957), who suggested that in the United States anomic conditions are prevalent and individualism is encouraged by cultural values, as represented by the American Dream. Merton's ideas about anomie, the American Dream, and individualism were further extended by Messner and Rosenfeld (1997) in Crime and the American Dream. They define the American Dream as "commitment to the goals of material success, to be pursued by everyone in society, under conditions of open, individual competition" (p. 164). They believe that American society is in a permanent state of anomie in which competitive individualism and weak social institutions lead many Americans to actively resist any institutional controls. Messner and Rosenfeld claim, "Americans are deeply committed to individual rights and individual autonomy" (p. 63). As a result, individualists tend to distrust government and oppose both governmental regulations and limitations on individual rights.

\section{Characterizing Individualism and Collectivism}

Although individualism and collectivism are sociologically conditioned traits that have been shown to directly affect attitudes and behavior (e.g., Triandis et al. 1995), the number of sociologically rooted quantitative studies examining these values is limited (Gouveia et al. 2003). Instead, the conceptual and empirical development of individualism and collectivism has occurred largely within a cross-cultural psychological framework.

Triandis et al. (1995) conceive of collectivism and individualism as a set of beliefs, norms, values, attitudes, and roles that are shared by people who speak the same language and live in the same geographical region during a particular historical time. In general, studies affirm the Durkheimian framework that individualistic tendencies are more prevalent in more advanced capitalistic economies and political democracies (e.g., Fine 1993). Whereas early researchers tended to agree that countries clearly err on the side of either individualism or collectivism, more recent scholars have argued that national cultures tend to combine elements of both - individualism and collectivism (Gudykunst et al. 1996). McAuliffe et al. (2003) found that one's behavior depends and is motivated by the groups' norms, which could be either individualistic or collectivistic irrespective of the national culture label.

In general, individualistic persons are defined as emotionally independent or "detached from community," and they tend to be self-contained, autonomous, and self-reliant (Bochner and Hesketh 1994; Jeffries, Schweitzer, and Morris 1973; Triandis et al. 1995). They are likely to value self-direction, power, and personal achievement (Ryckman and Houston 2003). On the other hand, those who hold collectivist orientations seem to be tightly integrated into their communities and let the needs of the group supersede their own interests (Bochner and Hesketh 1994; Triandis et al. 1995). 


\section{Definition of Utilitarian Individualism and Collectivism}

Following Bellah et al.'s (1985) conceptualization, utilitarian individualism is defined here as pursuing one's material goals in a self-reliant fashion. Thus, utilitarian individualism is closely associated with the values advanced by industrialized, capitalist democracies (Durkheim 1893/1964). In addition, utilitarian individualism is a centerpiece of the American Dream and an important cause of chronic anomic conditions in the United States (Merton 1957; Messner and Rosenfeld 1997). The second aspect of utilitarian individualism and the consequence of a strong belief in self-reliance is opposition toward governmental efforts to equalize citizens' economic position, to limit private business, and to build strong social programs that provide assistance to the most disadvantaged. In brief, "equal opportunity for all and special treatment for none is the individualistic creed" (Fine 1993: 56). Lipset (1990) agrees and points out that the United States is exceptional in that it has the lowest level of support among developed nations in providing assistance to the disadvantaged.

In contrast, utilitarian collectivism values group or community interests over selfinterest as demonstrated, for instance, by a willingness to share material resources with others outside of one's immediate family. Those components of collectivism have been defined by Jeffries et al. (1973) as cooperation-working together with others to achieve common goals-and collective responsibility-feeling responsible and providing assistance to others who are disadvantaged and in need.

\section{GUN OWNERSHIP AND ATTITUDES TOWARD GUN CONTROL}

This study examines whether the widespread gun ownership in the United States and prevailing positive attitudes toward gun control represent competing individualistic and collectivistic cultural traditions, respectively. The importance of individualism is evident in the historical tradition of gun ownership in the United States, the enduring profile of typical gun owners, and the subcultural behavior and values of some gun owners. On the other hand, the tendencies to control widespread gun ownership and to rely on government to provide security can be viewed as expressions of collectivistic values.

Legal gun owners, across time periods and data sources, possess several distinguishing attributes. Research suggests that legal gun owners are more likely to be White, male, and Protestant and from small towns and rural areas of the South (e.g., Dixon and Lizotte 1987; Wright and Marston 1975). A typical gun owner is also married and a Republican (Adams 1996). Gun ownership increases with age (Lizotte and Bordua 1980) and is highest among the middle aged (T. W. Smith 2001). Although Adams (1996) and T. W. Smith (2001) both find that gun ownership rates increase with income, T. W. Smith finds that education is a poor predictor of gun ownership. The traits of the typical gun owner-White, male, Protestant, middle class, and Republican—are also associated with individualism, an issue to be discussed later.

Although explanations of legal gun ownership vary, gun owners offer two principal justifications: defensive and recreational purposes. The research suggests that the majority of firearms are owned for recreational purposes (which includes 
sporting, hunting, and collecting), although the "hunting heritage" is declining (Spitzer 2004). Lizotte, Bordua, and White (1981) add that those who own guns for recreational use can be distinguished from other gun owners as they constitute a separate "sporting gun culture." The "recreational subculture" is transmitted intergenerationally and is positively associated with both Southern residence and defensive gun ownership. Thus, it seems plausible that this type of gun ownership, so closely related to the "frontier heritage," is also strongly associated with the values of utilitarian individualism: self-determination and self-reliance.

Another large category of weapon ownership comprises individuals who own guns for defensive purposes. Adams (1996) identifies two theoretical explanations of defensive gun ownership: acute fear of crime and past victimization experience as well as lack of faith in collective security. The first explanation has received mixed support (see, e.g., DeFronzo 1979 on the reciprocal relationship between fear of crime and weapon ownership). On the other hand, the second explanation finds broader support (Adams 1996; D. A. Smith and Uchida 1988) and can be viewed as an expression of individualistic values. These two explanations of defensive gun ownership, of course, may be mutually reinforcing.

Some sociologists link higher rates of weapon ownership in the South to higher violent crime rates in that region (Brennan, Lizotte, and McDowall 1993). One argument holds that a Southern subculture is characterized by the promotion of violent attitudes and behavior ( e.g., see D. Cohen et al. 1996 for a description of "Southern culture of honor"). An alternative interpretation is that structural forces, such as economic inequality and relative deprivation, cause both high gun ownership and violent crime rates (Dixon and Lizotte 1987). High rates of gun ownership in the South may also be rooted in higher levels of individualism. Thus, individualism may be a common thread in all explanations of gun ownership.

The present study is the first to empirically assess the link between individualism and collectivism, and gun ownership. However, different types of gun ownership overlap, making it impossible to select one category and analyze it separately. Although the impact of individualism on gun ownership may be contingent on the type of gun ownership, the impact of individualism on attitudes toward the toughening of gun control should be relatively unambiguous. It is proposed here that those who oppose gun control tend to hold individualistic views and by opposing any limitations on gun ownership, they seek to protect their own selfinterest, that of their families, and the interests of those with whom they closely affiliate, associate, or identify. Opposition to gun control may also reflect individualists' philosophical opposition to expansive, intrusive government, irrespective of their gun owner status.

If opposition to gun control is rooted in America's enduring tradition of individualism and support for gun control is rooted in equally entrenched collectivistic strains of American culture (Bellah et al. 1985), gun control attitudes should show stability over time. Indeed, E. Smith (1996) reports that according to selected public opinion polls, attitudes toward gun control have been stable since the 1960s. Support for gun control measures, especially gun permits and banning assault weapons, has always been high, whereas a stable, vocal minority has 
vehemently opposed gun control. In brief, females, liberals, and residents of urban areas, especially in the Northeast, are more likely than their counterparts to be proponents of gun control measures (Kleck 1996; T. W. Smith 1980). The evidence with respect to whether a person's social standing affects attitudes toward gun control is contradictory (see T. W. Smith 2001 vs. Kleck 1996). The ownership of guns remains the strongest predictor of attitudes toward gun control laws (Kleck 1996). The typical opponent of gun control measures, like the typical gun owner, is a White Protestant male who lives in a rural region outside of the Northwest (T. W. Smith 1980).

Heated rhetorical debates invariably follow proposals to strengthen the control of guns. The battle lines in this debate mark the divide in American culture between individualistic and collectivistic values.

Its opponents frame gun control as an infringement of individual rights as protected by the Second Amendment to the Constitution. They claim that the amendment grants law-abiding citizens the right to own firearms as a defense against intrusive government (Kates 1994).

On the other hand, the proponents of gun controls take a more collectivist position. First, they argue that the Second Amendment was meant not to preserve individual rights but rather to protect the states from an intrusive national government (McClurg 1992). The Supreme Court supports such an interpretation (Spitzer 2004). Second, the proponents of gun control also emphasize the public safety benefits of limiting access to guns.

Whether stricter gun control serves the common good with respect to public safety is subject to intense debate. Proponents of gun control measures believe that widespread ownership of guns leads to higher violent crime rates (Bellesiles 2000; Stark 1990). Therefore, additional restrictions on the distribution of guns would provide a safer environment. Opponents of gun control measures counter that guns are used often for self-defense, which deters some potential criminals from committing crimes in the first place. Therefore, impeding the access of lawabiding citizens to guns threatens to increase crime (Kleck 1996; Lott 2000).

\section{Studies Linking the Gun Issues with Individualism and Collectivism}

Some researchers of gun attitudes and behavior have posited an important role for the values of individualism and collectivism. McDowall and Loftin (1983) argue that some people arm themselves because they believe the government is not able to provide protection. McDowall and Loftin depict gun ownership as an "individual security measure with the expected benefits accruing for the most part to the gun owners and their household" (p. 1157). Adopting a DurkheimianMertonian framework, they argue that individuals who do not rely on law enforcement for providing protection (thus abandoning institutionalized collective means) purchase guns to achieve the individualistic goals of protecting themselves and family-even if collective security might suffer. To lend moral legitimacy to their individualistic motives, gun owners frequently evoke the rhetoric of protection and individual rights, citing the Second Amendment of the Constitution. Thus, the opponents of gun control measures focus on securing their individual 
rights even if the collectivity could benefit from restrictions of the distribution of guns.

In 2000, Cooke and Puddifoot found and reported that women in the United States were more likely than those in the United Kingdom to view guns as expressions of freedom and independence, whereas the U.K. women perceived guns as representing violence. However, neither group believed that guns deter crime. When one considers that most Americans believe that gun control measures would benefit society as a whole (McDowall and Loftin 1983) and that gun ownership does not deter crime (Cooke and Puddifoot 2000), one might conclude that there is possibly a cultural explanation of gun ownership in America. In addition, the primacy of gun ownership as a predictor of opposition to gun control measures suggests that self-interest, a core component of utilitarian individualism (Wolpert and Gimpel 1998), plays an important role in sustaining opposition to gun control measures.

More recently, Vizzard (2000) suggests that the conflict over gun control measures is "a conflict over ideas, values, perceptions, and most of all, the role of government" (p. 5). Specifically, he holds that the pivotal divide is between collectivistic and individualistic perspectives. Spitzer (2004) adds that the controversy around gun issues is fundamentally a clash between the individual rights of gun owners and the public collective interest in controlling crime (which he also calls a security dilemma). Not surprisingly, gun control opponents seem to perceive any restrictions on gun ownership as invading their individual liberty (McClurg 1992). McClurg (1992) states, "With respect to gun control, the conflict is one between community and individual rights" (p. 110).

Furthermore, contemporary anomie theorists have made a connection between anomic conditions in America, which are rooted in excessive individualism, and its high rate of gun ownership and gun violence. Messner and Rosenfeld (1997) assert that "an adequate explanation of gun-related violence must account for those qualities of the cultural 'rules' that make Americans unusually willing to deploy the means of final resort in dealing with perceived threats and interpersonal disputes" (p. 23).

Although many have theoretically linked gun attitudes and behavior to individualism and collectivism and research on the predictors of gun attitudes and behavior is consistent with research on correlates of individualism and collectivism, no study has directly measured the association between individualistic or collectivistic values and gun-related attitudes and behavior. The present study is the first to empirically assess the link between individualism and collectivism, and gun ownership and attitudes toward gun permits.

\section{METHOD}

\section{Data}

To assess the importance of individualism and collectivism in predicting gun ownership and attitudes toward gun control, data from the 1972-1998 General Social Survey (GSS), available from the Inter-University Consortium for Political and Social Research, was employed (Davis and Smith 1998). The GSS is the only 
survey data set that combines items related to individualism and collectivism in their utilitarian sense (see Burns 1992; S. M. Cohen and Liebman 1997; MarchantShapiro and Patterson 1995; T. W. Smith 1980), legal gun ownership, and attitudes toward gun control issues. In addition, the GSS is nationally representative and contains the relevant control variables indicated by prior research. Accordingly, the GSS remains the most popular data source in studies on gun ownership and attitudes toward gun control (e.g., Dixon and Lizotte 1987; Kleck 1996; O'Connor and Lizotte 1978; Wright and Marston 1975).

The GSS uses a multistage, stratified probability sample of clusters of households (Davis and Smith 1992). Data are collected annually (with several exceptions) and are representative of English-speaking adults at least eighteen years old. Reporting rates differ by age, and the best coverage is obtained for adults between the ages of twenty-five and sixty-four. Davis and Smith (1992) report that the response rate is high, ranging from 73.5 percent to 79.4 percent over the years. To gain precision with larger sample size and to generalize the findings, the authors suggest using multiple years in statistical analyses.

\section{Sample}

This research uses two samples from the GSS-compiled file. It uses the 1984 through 1998 waves of the GSS, excluding years when the surveys were not conducted (1985, 1986, 1992, 1995, and 1997). The sample consists of 7,174 individuals. A subsample comprising 1,191 participants from the 1984 survey wave is used for initial analysis of the index of individualism and collectivism (I-C Index 1). The 1984 wave was the first and only year in which the GSS includes all nine core questions that compose the I-C Index 1 . The proxy of the I-C Index 1, the I-C Index 2, represents the latent variables of individualism and collectivism based on four questions from the 1984 through 1998 waves.

The concepts of individualism and collectivism are multidimensional, and researchers frequently include a range of different items in their constructs. Some scholars situate collectivism and individualism on opposite sides of a continuum (Triandis et al. 1995). Very recently, however, Ryckman and Houston (2003) and Gouveia et al. (2003) argue that a multidimensional conceptualization of individualism and collectivism is preferable to a unidimensional index. However, this study employs a very specific and narrow economic/utilitarian meaning of these cultural values, and therefore a unidimensional index is appropriate.

Individualism and collectivism are indexed in this study as a single continuous variable, with the lowest score indicating extreme collectivism and the highest score indicating extreme individualism. All items of the I-C Index 1 and the I-C Index 2 contain Likert-type scale responses. The I-C Index 1 extends the scale of individualism proposed by Burns (1992) in his article on predicting political orientation. Notably, Burns used two items from the 1984 GSS data-"one's own efforts don't count" and "personal income not determined by work" - to represent the latent variable of individualism. Other three items available only in the 1984 sample are as follows: "should government reduce income differences?" "government should insure jobs and stable prices," and "responsibility of government 
to meet needs." Four other variables- "should government improve standard of living?" "should government do more or less?" "should government help pay for medical care?" and "should government aid Blacks?"-represent the component of individualism and collectivism that addresses the issues of promoting equal distribution of wealth, social programs, and the government intervening on behalf of the poor and disadvantaged (S. M. Cohen and Liebman 1997; MarchantShapiro and Patterson 1995). Our measures assume that the espousal of self-reliance implies opposition to redistributive government intervention and vice versa. Agreement with the items indicates collectivism, and disagreement with the items indicates high levels of individualism.

\section{Independent Variables}

The standard variables employed by researchers who used the GSS in studies on gun ownership and attitudes toward gun control and demographic variables related to individualism and collectivism were included in the analysis. Control variables consist of age, sex, race, income, marital status, religion, education, region, urbanization, and political views. Besides these variables, four additional control variables are included in the analysis to weigh individualism and collectivism against competing explanations of gun ownership-prior fear and victimization and recreational gun use. Fear of crime is measured as being afraid to walk at night in one's neighborhood, and two variables represent a prior respondent's victimization experience: being burglarized and being robbed during the past year. Finally, recreational gun ownership is measured by a question on a respondent's hunting status. All four variables are dichotomous. The coding scheme, means, and standard deviations of the variables employed in this article are presented in Table 1.

In addition, the analysis considers several possible interaction terms. It is hypothesized that the effects of individualism vary depending on whether one is a gun owner, a hunter, or a resident of the Mountain or Southern regions. Many criminologists note that those who live in the South or in the Mountain region or those who are hunters belong to a distinctive subculture (Lizotte et al. 1981; Spitzer 2004). Thus, hunters and individuals who live in the South or Mountain region might be a group of gun owners who are more likely to hold individualistic values. A similar explanation applies when predicting attitudes toward gun control. In addition, because criminologists tend to agree that gun ownership is the most important predictor of attitudes toward gun control (e.g., see Kleck 1996), it is hypothesized that the individualistic gun owners are those individuals who are the strongest opponents of gun control.

\section{Index of Individualism and Collectivism}

Based on theoretical definitions and previous studies, an unobserved latent construct of individualism and collectivism was created. As mentioned previously, the I-C Index 1 includes all nine indicators and the I-C Index 2 includes a subset of four indicators. The indices comprise aggregated standardized items. 
TABLE 1

Sample Descriptive Characteristics: The 1984 and the 1984-1998 Samples

\begin{tabular}{|c|c|c|c|}
\hline Variable & $M$ & $S D$ & $N$ \\
\hline I-C Index 1 (collectivistic-individualistic)a & 0.11 & 5.54 & 1,191 \\
\hline I-C Index $2^{b}$ & 0.00 & 2.91 & 7,174 \\
\hline Political views $(1=\text { liberal, } 7=\text { conservative })^{\mathrm{a}}$ & 4.16 & 1.28 & 1,165 \\
\hline Political views ${ }^{\mathrm{b}}$ & 4.12 & 1.36 & 6,886 \\
\hline Age $(18 \text { to } 89)^{a}$ & 43.13 & 17.39 & 1,190 \\
\hline Age $^{b}$ & 44.65 & 17.19 & 7,160 \\
\hline Education (highest year completed: 0 to 20$)^{\mathrm{a}}$ & 12.57 & 3.05 & 1,190 \\
\hline Education $^{\mathrm{b}}$ & 12.89 & 3.04 & 7,162 \\
\hline Marital status $(1=\text { married, } 0=\text { not married })^{\mathrm{a}}$ & 0.57 & 0.50 & 1,191 \\
\hline Marital status ${ }^{\mathrm{b}}$ & 0.52 & 0.50 & 7,174 \\
\hline Race $(1=\text { White }, 0=\text { other })^{\mathrm{a}}$ & 0.85 & 0.36 & 1,191 \\
\hline Race $^{\text {b }}$ & 0.80 & 0.40 & 7,174 \\
\hline Religion $(1=\text { Protestant, } 0=\text { other })^{\mathrm{a}}$ & 0.63 & 0.48 & 1,191 \\
\hline Religion ${ }^{\mathrm{b}}$ & 0.63 & 0.48 & 7,174 \\
\hline Gender $(1=\text { male, } 0=\text { female })^{\mathrm{a}}$ & 0.44 & 0.50 & 1,191 \\
\hline Gender ${ }^{b}$ & 0.45 & 0.50 & 7,174 \\
\hline Region $1(1=\text { South }, 0=\text { other })^{\mathrm{a}}$ & 0.34 & 0.48 & 1,191 \\
\hline Region $1^{\mathrm{b}}$ & 0.35 & 0.48 & 7,174 \\
\hline Region $2(1=\text { Mountain, } 0=\text { other })^{\mathrm{a}}$ & 0.06 & 0.24 & 1,191 \\
\hline Region $2^{\mathrm{b}}$ & 0.06 & 0.24 & 7,174 \\
\hline Household gun ownership $(1=\text { own, } 0=\text { does not own })^{a}$ & 0.47 & 0.50 & 1,191 \\
\hline Household gun ownership ${ }^{\mathrm{b}}$ & 0.42 & 0.49 & 7,174 \\
\hline Individual gun ownership $(1=\text { own, } 0=\text { does not own })^{\mathrm{a}}$ & 0.27 & 0.45 & 1,191 \\
\hline Individual gun ownership ${ }^{\mathrm{b}}$ & 0.27 & 0.45 & 7,174 \\
\hline Urbanization $(1=\text { rural, } 0=\text { urban })^{\mathrm{a}}$ & 0.47 & 0.50 & 1,191 \\
\hline Urbanization $^{\mathrm{b}}$ & 0.49 & 0.50 & 7,174 \\
\hline Income (annual income, twelve categories) ${ }^{\mathrm{a}}$ & 9.71 & 2.84 & 1,115 \\
\hline Income $^{\mathrm{b}}$ & 10.33 & 2.69 & 6,886 \\
\hline Hunting $(1=\text { hunter }, 0=\text { not hunter })^{\mathrm{a}}$ & 0.16 & 0.36 & 1,191 \\
\hline Hunting $\mathrm{b}$ & 0.22 & 0.41 & 7,174 \\
\hline Attitudes toward gun permits $(1=\text { oppose }, 0=\text { favor })^{\mathrm{a}}$ & 0.28 & 0.45 & 1,191 \\
\hline Attitudes toward gun permits ${ }^{b}$ & 0.23 & 0.42 & 7,174 \\
\hline Fear of crime $(1=\text { fear, } 0=\text { no fear })^{\mathrm{a}}$ & 0.41 & 0.49 & 1,191 \\
\hline Fear of crime ${ }^{b}$ & 0.41 & 0.49 & 7,174 \\
\hline $\begin{array}{l}\text { Victim of burglary }(1=\text { burglarized last year, } 0=\text { not burglarized } \\
\text { last year })^{\mathrm{a}}\end{array}$ & 0.07 & 0.25 & 1,191 \\
\hline Victim of burglary ${ }^{\mathrm{b}}$ & 0.04 & 0.21 & 7,174 \\
\hline Victim of robbery $(1=\text { robbed last year, } 0=\text { not robbed last year })^{\mathrm{a}}$ & 0.02 & 0.14 & 1,191 \\
\hline Victim of robbery ${ }^{b}$ & 0.01 & 0.11 & 7,174 \\
\hline
\end{tabular}

Note: I-C Index = index of individualism and collectivism.

aThe 1984 sample.

${ }^{\mathrm{b}}$ The 1984-1998 sample. 
TABLE 2

Index of Individualism and Collectivism Reliability and Factor Analysis, $1984(N=1,191)$

\begin{tabular}{lccc}
\hline Item & Extraction & Eiqenvalue & Component \\
\hline I-C Index 1 & & & \\
Government should insure jobs and stable prices. & .43 & 3.47 & .19 \\
Responsibility of government to meet needs. & .53 & 0.99 & .21 \\
One's own efforts do not count. & .25 & 0.86 & .14 \\
Personal income not determined by work. & .38 & 0.78 & .18 \\
Should government reduce income differences? & .37 & 0.68 & .18 \\
Should government improve standard of living? & .48 & 0.63 & .20 \\
Should government do more or less? & .46 & 0.60 & .19 \\
Should government help pay for medical care? & .37 & 0.52 & .18 \\
Should government aid Blacks? & .22 & 0.46 & .13 \\
I-C Index 2 & & & \\
Should government improve standard of living? & .63 & 2.04 & .37 \\
Should government do more or less? & .52 & 0.81 & .34 \\
Should government help pay for medical care? & .55 & 0.63 & .31 \\
Should government aid Blacks? & .33 & 0.52 & .34 \\
\hline
\end{tabular}

Note: I-C Index = index of individualism and collectivism.

The standardized item alpha of the I-C Index 1 was .80 , indicating that the index is internally consistent and reliable. Additionally, the results of the principle component not-rotated factor analysis reveal that all index items load on one component (see Table 2), lending support to a unidimensional conceptualization of the index. The component score coefficient matrix (last column in Table 2) indicates that the items are equally well correlated, so the scale can be used without weighting.

The I-C Index 2, which substitutes for the I-C Index 1 in analysis using the full (pooled) sample, is also reliable (Cronbach's alpha $=.70)$. Likewise, all the index items loaded on one component. The values of I-C Index 1 (and I-C Index 2) range from -13.19 units ( -6.45 units) representing extreme collectivism to 14.06 units (6.75 units) representing extreme individualism. To test whether the I-C Index 2 with four variables is an adequate proxy for the I-C Index 1 with nine variables, Pearson's correlation was obtained. The correlation between two indices is large and significant (i.e., $r=.863 ; p<.01$ ), indicating that the I-C Index 2 is an acceptable proxy for the I-C Index 1 .

\section{Dependent Variables}

This analysis assessed two outcomes: gun ownership and attitudes toward gun control. The former construct was measured at both the household and the individual respondent level. The attitudes of individual respondents toward gun ownership are more pertinent to the present study of the consequences of individualism versus collectivism. However, discrepancies in reporting practices between males and females (males might be more likely to report their gun ownership than females, because men are more likely to be hunters and gun collectors) 
necessitate the use of a household gun ownership measure to cross-validate individual reports. The question on household gun ownership states, "Do you happen to have in your home any guns or revolvers?" and the question on the respondent's gun ownership states, "Do any of these guns personally belong to you?"

The next dependent variable assesses attitudes toward gun control measures. This variable is represented by a single question: "Would you favor or oppose a law which would require a person to obtain a police permit before he or she could buy a gun?" This is the only question on the GSS that focuses on the respondent's attitudes toward gun control. The question on attitudes toward gun permits is well suited for this study, because it asks about the least intrusive and conservative gun control measure. The purpose of police permits is to run a criminal background check on individuals who plan to purchase a gun. Although it might affect the speed of obtaining a gun for law-abiding citizens, it allows for weeding out individuals who legally should not be able to purchase a gun. Therefore, favoring permits is quite popular, and most Americans support this gun control measure. It is plausible that opposing gun permits indeed might be a direct function of self-interest and individualistic values.

\section{RESULTS}

\section{Multivariate Analysis}

A regression analysis tests the relationship between individualistic and collectivistic values, and a set of demographic variables. In this analysis, the index of individualism and collectivism is modeled in both the 1984 and 1984-1998 samples as a function of gender, marital status, religion, income, education, race, political views, age, residence in the South or in the Mountain region, and urbanization.

The results for the 1984 and 1984-1998 samples demonstrate income, education, race, gender, religion, age, political views, and residing in the South or the Mountain region $(p<.01)$ all predict the I-C Index 1 and I-C Index 2 in an expected manner.

Thus, individualists tend to have higher income, have higher education, and reside in the South or in the Mountain region. They are also more likely to be White males of Protestant beliefs and with conservative political views. Two variables, marital status and urbanization, do not significantly explain the values of individualism and collectivism. The fact that marital status does not predict the values of individualism and collectivism is surprising because the cross-national research suggests that single people tend to be more individualistic. Contrary to expectations suggested by prior studies, older individuals tend to be more individualistic. However, the fact that age is a predictor of individualism makes sense because the index measures utilitarian individualism and collectivism, and this construct is closely related to the socioeconomic status. This statement is further supported by the fact that White racial status is the strongest predictor of individualism. Thus, minorities, disadvantaged, and people from the lower socioeconomic strata tend to be more collectivistic. 
TABLE 3

Unadjusted OLS Regression Coefficient of Analytic Variables Predicting I-C Index $2(N=6,614, R$-squared $=.222)$

\begin{tabular}{llr}
\hline Variable & \multicolumn{1}{c}{$B(S E)$} & \multicolumn{1}{c}{$t$} \\
\hline Protestant & $0.21^{*}(.07)$ & 3.03 \\
Income & $0.11^{*}(.01)$ & 8.44 \\
Education & $8.74 \mathrm{E}-02^{*}(.01)$ & 7.52 \\
White & $2.14^{*}(.09)$ & 25.26 \\
Political views & $0.48^{*}(.02)$ & 20.50 \\
Age & $1.27 \mathrm{E}-02^{*}(.00)$ & 6.54 \\
Married & $9.07 \mathrm{E}-02(.07)$ & 1.33 \\
Male & $0.22^{*}(.06)$ & 3.49 \\
South & $0.49^{*}(.07)$ & 7.04 \\
Mountain & $0.51^{*}(.13)$ & 3.87 \\
Rural & $6.98 \mathrm{E}-02(.07)$ & 1.06 \\
Constant & $-7.06^{*}(.23)$ & -31.09 \\
\hline
\end{tabular}

Note: OLS = ordinary least squares; I-C Index = index of individualism and collectivism. ${ }^{*} p<.01$.

A number of separate logistic regression models were estimated using both the 1984 and 1984-1998 samples and household as well as individual gun ownership. The central purpose of the logit analysis is to assess whether the index of individualism-collectivism predicts gun ownership and attitudes toward gun control net of established and hypothesized joint predictors of individualism and gun attitudes and ownership. Thus, some variables that do not enhance the overall fit of the model were retained in the multivariate models for theoretical reasons (most prominently fear of crime and prior victimization).

In the 1984 sample, the following variables are significant in predicting the respondent's gun ownership: gender, age, urbanization, the Southern residence, religion, hunting status, income, political views, and marital status (see Table 4, Model 1). A similar pattern emerges for the full sample, as displayed in Model 2 of Table 4. Also of note, fear, burglary, and robbery fail to attain statistical significance. Statistically significant results are easier to obtain in large samples; thus, it is pertinent to consider the relative magnitude of the effects as well, via the odds ratios. Controlling for all the other variables in the model, hunting status and gender demonstrate the greatest influence on gun ownership. Specifically, males were more than 5 times as likely as females to report gun ownership. Not surprisingly, individuals who engaged in recreational hunting had a much greater likelihood of gun ownership as compared to nonowners (odds ratio $=6.00$ ). Residents of rural areas, depending on the sample size (Model 1 vs. Model 2), are approximately twice as likely as residents of urban areas to report gun ownership. Although the I-C Index 1 in a smaller sample does not appear to be significant, the I-C Index 2 is significant at $p<.01$. In the enlarged sample, a one unit increase in individualism increases the predicted odds of gun ownership by 5 percent. 
TABLE 4

Multivariate Logistic Regression Predicting Respondent's Gun Ownership

\begin{tabular}{|c|c|c|c|c|}
\hline \multirow[b]{2}{*}{ Variable } & \multicolumn{2}{|c|}{ Model 1} & \multicolumn{2}{|c|}{ Model 2} \\
\hline & $B(S E)$ & Odds Ratio & $B(S E)$ & Odds Ratio \\
\hline Index 1 & $0.02(.02)$ & 1.02 & & \\
\hline Index 2 & & & $0.05^{* *}(.01)$ & 1.05 \\
\hline Fear & $-0.18(.20)$ & 0.83 & $-0.06(.08)$ & 0.94 \\
\hline Burglary & $0.64(.34)$ & 1.90 & $0.24(.17)$ & 1.27 \\
\hline Robbery & $-0.26(.84)$ & 0.77 & $0.20(.34)$ & 1.22 \\
\hline Hunting & $1.79^{* *}(.23)$ & 6.00 & $1.01^{* *}(.10)$ & 7.45 \\
\hline South & $0.51^{* *}(.19)$ & 1.66 & $0.43^{* *}(.07)$ & 1.53 \\
\hline Mountain West & $0.20(.34)$ & 1.23 & $0.49^{* *}(.13)$ & 1.63 \\
\hline Rural & $0.85^{* *}(.18)$ & 2.36 & $0.58^{* *}(.07)$ & 1.79 \\
\hline Education & $-0.06(.03)$ & 0.94 & $-0.06^{* *}(.01)$ & 0.94 \\
\hline Income & $0.14^{* *}(.04)$ & 1.15 & $0.09^{* *}(.02)$ & 1.10 \\
\hline White & $0.44(.28)$ & 1.55 & $0.28^{*}(.10)$ & 1.33 \\
\hline Male & $1.67^{* *}(.20)$ & 5.31 & $1.64^{* *}(.08)$ & 5.14 \\
\hline Protestant & $0.53^{* *}(.19)$ & 1.71 & $0.52^{* *}(.08)$ & 1.68 \\
\hline Married & $-002^{* *}(.19)$ & 1.00 & $0.17^{*}(.07)$ & 1.19 \\
\hline Age & $0.03^{* *}(.01)$ & 1.10 & $0.02^{* *}(.00)$ & 1.02 \\
\hline Political views & $0.19^{* *}(.07)$ & 1.21 & $0.05^{*}(.03)$ & 1.06 \\
\hline Constant & $-6.36^{* *}(.78)$ & & $-4.80 * *(.29)$ & \\
\hline Model chi-square & $383.65(d f=16)$ & & $2,153.39(d f=16)$ & \\
\hline
\end{tabular}

Note: Model 1: 1984, $N=1,093$ and Model 2: 1984 to 1998, $N=6,615$.

${ }^{*} p<.05 ;{ }^{* *} p<.01$.

Household gun ownership was modeled in the same fashion. The positive effect of the I-C Index 1 is only marginally significant in the 1984 sample $(p<.1)$. In the enlarged sample, the coefficient of the I-C Index 2 is small but significant at $p<.01$.

To summarize, in the enlarged sample, private and household gun ownership is related to being Protestant, married, older, White, and male. Gun owners on average appear to have lower education and higher income net of the other factors. They are concentrated in the rural regions of the South or the Mountain West. Gun owners tend to hold individualistic values and conservative political views. In these analyses, fear of crime is not statistically related to gun ownership. Similarly, being victimized (i.e., robbed or burglarized) is not significantly related to gun ownership. The odds ratios suggest that the most influential variables are gender and hunting status.

Next, logistic regressions models of attitudes toward gun permits were estimated. The following variables were significantly $(p<.05)$ and predictably associated with opposition to gun permits in the 1984 sample: gun ownership (individual and household), I-C Index 1, income, being a hunter, political views, marital status, and religion (see Table 5, Model 3). In the model of respondent's gun ownership, unlike the model with household gun ownership, gender is no longer statistically significant, but race is. White respondents are more likely to oppose gun 
TABLE 5

Multivariate Logistic Regression Predicting Opposition to Gun Permits

\begin{tabular}{|c|c|c|c|c|}
\hline \multirow[b]{2}{*}{ Variable } & \multicolumn{2}{|c|}{ Model 3} & \multicolumn{2}{|c|}{ Model 4} \\
\hline & $B(S E)$ & Odds Ratio & $B(S E)$ & Odds Ratio \\
\hline Index 1 & $0.06^{* *}(.02)$ & 1.06 & & \\
\hline Index 2 & & & $0.09^{* *}(.01)$ & 1.10 \\
\hline $\begin{array}{l}\text { Respondent } \\
\text { owns a gun }\end{array}$ & $1.12^{* *}(.18)$ & 3.05 & $0.96^{* *}(.08)$ & 2.61 \\
\hline Fear & $0.00(.17)$ & 1.00 & $-0.17^{*}(07)$ & 0.84 \\
\hline Burglary & $0.08(.31)$ & 1.08 & $0.01(.16)$ & 1.01 \\
\hline Robbery & $0.52(.58)$ & 1.67 & $0.63^{*}(.29)$ & 1.88 \\
\hline Hunting & $0.62^{* *}(.22)$ & 1.86 & $0.59 * *(.09)$ & 1.80 \\
\hline South & $0.18(.17)$ & 1.20 & $0.11(.07)$ & 1.11 \\
\hline Mountain West & $0.44(.29)$ & 1.56 & $0.56^{* *}(.12)$ & 1.75 \\
\hline Rural & $-0.02(.16)$ & 1.02 & $0.30^{* *}(.07)$ & 1.36 \\
\hline Education & $-0.03(.03)$ & 0.97 & $-0.03^{*}(.01)$ & 0.97 \\
\hline Income & $-0.10^{* *}(.03)$ & 0.91 & $-0.05^{* *}(.01)$ & 0.96 \\
\hline White & $0.56^{*}(.26)$ & 1.74 & $0.08(.10)$ & 1.09 \\
\hline Male & $0.10(.19)$ & 1.11 & $0.25^{* *}(.08)$ & 1.28 \\
\hline Protestant & $0.45^{* *}(.17)$ & 1.56 & $0.18^{*}(.07)$ & 1.20 \\
\hline Married & $0.50^{* *}(.17)$ & 1.65 & $0.11(.07)$ & 1.12 \\
\hline Age & $-0.01(.01)$ & 0.99 & $-0.004(.00)$ & 1.00 \\
\hline Political views & $0.17^{* *}(.06)$ & 1.18 & $0.06^{*}(.03)$ & 1.06 \\
\hline Constant & $-1.84^{* *}(.64)$ & & $-1.45^{* *}(.25)$ & \\
\hline Model chi-square & $190.25(d f=17)$ & & $815.20(d f=17)$ & \\
\hline
\end{tabular}

Note: Model 3: 1984, $N=1,093$ and Model 4: 1984 to $1998, N=6,615$.

${ }^{*} p<.05 ;{ }^{* *} p<.01$.

control than respondents of other ethnic groups. The measures of fear of crime and prior victimization are not significant.

Thus, those who oppose gun control measures tend to be married, politically conservative gun owners and hunters. Their incomes are also lower relative to gun control opponents. The odds of being an opponent of gun permits are more than 3 times as high for gun owners (versus nonowners) and nearly twice as high when the respondent is a hunter (versus nonhunter), controlling for other variables in the model. Holding individualistic values increases the odds of opposing gun permits by 6 percent after controlling for other variables in the model, whether including household or individual gun ownership.

Model 4 in Table 5 presents the multivariate results for the entire sample based on the 1984-1998 data. The following variables are positive predictors in both models $(p<.01)$ : I-C Index 2, gender, urbanization, the Mountain region, Protestantism $(p<$ $.05)$, hunting status, respondent's (or household) gun ownership, political views $(p<.05)$, and being a victim of robbery in the past year $(p<.05)$. Education, income $(p<.01)$, and fear of crime have negative relationships with favorable attitudes toward gun control $(p<.05)$. Five variables-age, race, the South, marital status, and being burglarized-are not significant in the models derived from the 1984-1998 samples. 
Gun ownership, hunting status, and residing in the Mountain region are the strongest predictors of attitudes toward gun permits. The odds of opposing gun control are nearly triple when the respondent owns a gun (2.61). Being a hunter and residing in the Mountain region increases the odds of opposing gun control by 80 percent and 75 percent, respectively. Holding individualistic values is a consistent strong predictor of opposing gun control measures in all attitudinal models. It increases the odds of opposing gun permits by 10 percent after controlling for other variables in the model.

To explore further the role of individualism and collectivism in gun issues, all the models were regressed again but without the indices. All of the 1984 models had lower model Chi-squares than the models with the I-C Index 1 . In contrast to all other models, the model with attitudes toward gun permits when the respondent's gun ownership is one of the control variables correctly specified the higher percentage of cases than the models with the I-C Index 1 . However, the differences are not large. After deleting the I-C Index 1, race was significant the most often-3 times. This finding suggests that being White is related to the I-C Index 1 . This is plausible due to utilitarian individualism's close association with socioeconomic status.

When considering the 1984-1998 models, the values of the model Chi-square without the I-C Index 2 are lower than the values of Chi-squares with the index. No pattern was detected in identifying variables that became significant after removing the I-C Index 2 from the models. Thus, these results suggest that the values of individualism have consistently predicted some gun ownership models and attitudes toward gun permits.

Finally, additional analysis (not shown) included estimating logistic regression models with interaction terms. The results of logistic regression with respondent's gun ownership as a dependent variable indicate that all control variables- the index of individualism and collectivism, being a hunter, residing in the Mountain region, and residing in the South-remain statistically significant. The interaction between the I-C Index 2 and hunting status and between the I-C Index 2 and the South are not statistically significant. The interaction between the I-C Index 2 and residing in the Mountain region is significant at $p<.05$. In additional logistic models with the attitudes toward gun control as a dependent variable, the index of individualism and collectivism, respondent gun ownership, living in the Mountain region or in the South, and being a hunter are statistically significant. None of the interactions between the I-C Index 2 and mentioned variables are statistically significant. The results suggest that the effects of individualism and collectivism do not vary by gun ownership, hunting status, or the Southern residence. On the other hand, living in the Mountain region and being individualistic increase the odds of owning the gun by a factor of 1.13 holding other variables constant. The main effect of the I-C Index 2 remains significant. Being individualistic increases the odds of gun ownership by 4 percent, holding other variables constant.

\section{DISCUSSION}

This research is an attempt to address the dearth of sociological research that employs the constructs of individualism and collectivism to explain sociological phenomena-including the controversial terrain of gun ownership and attitudes 
toward gun control in America. The utilitarian component of individualism and collectivism seems especially important in light of Durkheim's classical theory, description of the American Dream by Messner and Rosenfeld (1997), and contemporary concerns about excessive individualism expressed by Bellah et al. (1985) and Putnam (2000), among others.

Extending the work of Burns (1992) and borrowing from the extensive theoretical sociological literature and experimental cross-national psychological literature on individualism, the present study employed the GSS to create a onedimensional index of utilitarian individualism and its opposite, collectivism. The index was shown to be a reliable measure that was tested as a predictor of legal gun ownership and attitudes toward gun permits in the United States.

The results demonstrate that, in fact, these cultural values do explain some gun ownership and predict attitudes toward gun permits. Specifically, the index of individualism and collectivism was a significant predictor of household and respondent gun ownership in the enlarged sample. Even more importantly, individualism appears to be one of the main predictors of attitudes against gun permits. Having individualistic values is a consistent predictor in all logistic models, regardless of the sample size and the type of gun ownership (whether individual or household). Consistently, being more individualistic than collectivistic increases the odds of opposing gun permits. Finally, the index of individualism and collectivism remains significant when estimating the models with relevant interaction terms.

Some limitations of this research bear mention and should be addressed by future research. First, the GSS data are limited to legal gun owners and include only a single-item measure of gun control attitudes. The selection of questions to describe utilitarian individualism and collectivism was limited, except in the 1984 sample. Finally, the data do not allow for constructing indices of other types of individualism, notably expressive individualism.

Nonetheless, this study marks an important step in systematically assessing the influence of an important cultural value on gun ownership and attitudes toward gun control. This research can offer a model to other researchers seeking to uncover the cultural foundations of public support for other social and justice policies.

Acknowledgments: This article was supported in part by the National Institute of Mental Health (Grant \#5-T32-MH16242). An earlier version of this article was presented at the 2002 annual meeting of the American Sociological Association in Chicago. I thank Richard Serpe and the anonymous reviewers for their helpful comments. I am also grateful to Matthew Burbank, Thomas Burns, Byron Davis, Paul Hirschfield, Allan Horwitz, and my colleagues/postdoctoral fellows at Rutgers University for their helpful suggestions and editorial assistance.

\section{REFERENCES}

Adams, Kenneth. 1996. "Guns and Gun Control." Pp. 109-24 in Americans View Crime and Justice. A National Public Opinion Survey, edited by T. J. Flanagan and D. R. Longmire. Thousand Oaks, CA: Sage. 
Bellah, Robert N., Richard Madsen, William M. Sullivan, Ann Swidler, and Steven M. Tipton. 1985. Habits of the Heart. Individualism and Commitment in American Life. Berkeley: University of California Press.

Bellesiles, Michael A. 2000. Arming America: The Origins of a National Gun Culture. New York: Alfred A. Knopf.

Besnard, Phillippe. 1993. "Anomie and Fatalism in Durkheim's Theory of Regulation." Pp. 16990 in Emile Durkheim. Sociologist and Moralist, edited by S. P. Turner. London: Routledge.

Bochner, Stephen and Beryl Hesketh. 1994. "Power Distance, Individualism/Collectivism, and Job Related Attitudes in a Culturally Diverse Work Group." Journal of Cross-Cultural Psychology 25(2): 233-57.

Brennan, Pauline G., Alan J. Lizotte, and David McDowall. 1993. “Guns, Southerness, and Gun Control." Journal of Quantitative Criminology 9(3): 289-307.

Burns, Thomas J. 1992. "Class Dimensions, Individualism, and Political Orientation." Sociological Spectrum 12: 349-62.

Cohen, Dov, Brian F. Bowdle, Richard E. Nisbett, and Norbert Schwarz. 1996. "Insult, Aggression, and the Southern Culture of Honor: An 'Experimental Ethnography.'" Journal of Personality and Social Psychology 70(5): 945-60.

Cohen, Steven M. and Charles Liebman. 1997. “American Jewish Liberalism. Unraveling the Strands." Public Opinion Quarterly 61: 405-30.

Cooke, Claire A. and John E. Puddifoot. 2000. "Gun Culture and Symbolism among U.K. and U.S. Women." The Journal of Social Psychology 140(4): 423-33.

Davis, James A. and Tom W. Smith . 1992. The NORC General Social Survey-A User's Guide. Newbury Park, CA: Sage.

and Tom W. Smith. 1998. General Social Surveys, 1972-1998 [machine-readable data file]. Principal Investigator, James A. Davis; Director and Co-Principal Investigator, Tom. W. Smith, Co-Principal Investigator, Peter V. Mardsen, National Opinion Research Center ed. Chicago: National Opinion Research Center, producer, 1998; Storrs, CT: The Roper Center for Public Opinion Research, University of Connecticut, distributor. 1 data file (38,116 logical records) and 1 codebook (1479 pp).

DeFronzo, James. 1979. "Fear of Crime and Handgun Ownership." Criminology 17(3): 331-39.

Dixon, Jo and Alan J. Lizotte. 1987. "Gun Ownership and the Southern Subculture of Violence." American Journal of Sociology 93(2): 383-405.

Durkheim, Emile. 1893/1964. The Division of Labor. New York: Free Press. 1897/1951. Suicide. New York: Free Press.

Fine, Terri Susan. 1993. "Social Position and Commitment to Core Values: Grappling with the (Non)Impact of Gender." Women and Politics 13(2): 53-72.

Gouveia, Valdiney V., Miguel Clemente, and Pablo Espinosa. 2003. "The Horizontal and Vertical Attributes of Individualism and Collectivism in a Spanish Population." The Journal of Social Psychology 143(1): 43-63.

Gudykunst, William B., Yuko Matsumoto, Stella Ting-Toomey, Tsukasa Nishida, Kwangsu Kim, and Sam Heyman. 1996. "The Influence of Cultural Individualism-Collectivism, Self Construals, and Individual Values on Communication Styles across Cultures." Human Communication Research 22(4): 510-43.

Jeffries, Vincent, David R. Schweitzer, and Richard T. Morris. 1973. “Values, Authoritarianism, and Antagonism toward Ethnic Minorities. A Swiss Replication." Pacific Sociological Review 16(3): 357-76.

Kates, Don B. 1994. "Gun Control: Separating Reality from Symbolism." Journal of Contemporary Law 20(2): 353-79. 
Kleck, Gary. 1996. "Crime, Culture Conflict and the Sources of Support for Gun Control. A Multilevel Application of the General Social Surveys." American Behavioral Scientist 39(4): 387-404.

Lipset, Seymour. 1990. Continental Divide. The Values and Institutions of the United States and Canada. New York: Routledge.

Lizotte, Alan J. and David J. Bordua. 1980. "Firearms Ownership for Sport and Protection: Two Divergent Models." American Sociological Review 45: 229-44.

- David J. Bordua, and Carolyn S. White. 1981. "Firearms Ownership for Sport and Protection: Two not so Divergent Models." American Sociological Review 46: 499-503.

Lott, John R., Jr. 2000. More Guns, Less Crime: Understanding Crime and Gun-Control Laws, 2nd ed. Chicago: University of Chicago Press.

Marchant-Shapiro, Theresa and Kelly D. Patterson. 1995. "Partisan Change in the Mountain West." Political Behavior 17(4): 359-78.

McAuliffe, Brendan J., Jolanda Jetten, Matthew J. Hornsey, and Michael A. Hogg. 2003. "Individualist and Collectivist Norms: When It's OK to Go Your Own Way." European Journal of Social Psychology 33: 57-70.

McClurg, Andrew J. 1992. "The Rhetoric of Gun Control." The American University Law Review 42(1): 53-113.

McDowall, David and Collin Loftin. 1983. "Collective Security and the Demand for Legal Handguns." American Journal of Sociology 88(6): 1146-61.

Merton, Robert K. 1957. Social Theory and Social Structure. Glencoe, IL: Free Press.

Messner, Steven F. and Richard Rosenfeld. 1997. Crime and the American Dream. Belmont, CA: Wadsworth Publishing Company.

O'Connor, James F. and Alan Lizotte. 1978. "The 'Southern Subculture of Violence' Thesis and Patterns of Gun Ownership." Social Problems 25: 420-29.

Putnam, Robert D. 2000. Bowling Alone. The Collapse and Revival of American Community. New York: Simon \& Schuster.

Ryckman, Richard M. and Diane M. Houston. 2003. "Value Priorities in American and British Female and Male University Students." The Journal of Social Psychology 143(1): 127-38.

Smith, Douglas A. and Craig D. Uchida. 1988. "The Social Organization of Self-Help: A Study of Defensive Weapon Ownership." American Sociological Review 53: 94-102.

Smith, Eric. 1996. "What Is Public Opinion?" Critical Review 10(1): 95-105.

Smith, Tom W. 1980. "The 75\% Solution: An Analysis of the Structure of Attitudes on Gun Control 1959-1977." The Journal of Criminal Law and Criminology 71(3): 300-16.

- 2001. 2001 National Gun Policy Survey of the National Opinion Research Center: Research Findings. Chicago: National Opinion Research Center, University of Chicago.

Spitzer, Robert J. 2004. The Politics of Gun Control. Washington, DC: CQ Press.

Stark, Evan. 1990. "Rethinking Homicide." International Journal of Health Services 20(1): 3-26.

Triandis, Harry C., Darius K. S. Chan, Dharm P. S. Bhawuk, Sumiko Iwao, and Jai B. P. Sinha. 1995. "Multimethod Probes of Allocentrism and Idiocentrism." International Journal of Psychology 30(4): 461-80.

Vizzard, William J. 2000. Shots in the Dark. The Policy, Politics, and Symbolism of Gun Control. Lanham, MD: Rowman \& Littlefield.

Wolpert, Robin M. and James G. Gimpel. 1998. "Self-Interest, Symbolic Politics, and Public Attitudes toward Gun Control." Political Behavior 20(3): 241-62.

Wright, James D. and Linda L. Marston. 1975. "The Ownership of the Means of Destruction: Weapons in the United States." Social Problems 23: 93-107. 

Reproduced with permission of the copyright owner. Further reproduction prohibited without permission. 